\title{
A origem dos planetas: Catorze bilhões de anos de evolução cósmica
}

\author{
The origin of the planets: Fourteen billion years of cosmic evolution
}

\author{
Mayra Meirelles Marques ${ }^{* 1[}$, Bruno Leonardo do Nascimento-Dias ${ }^{2}$ \\ ${ }^{1}$ Universidade Federal do Rio de Janeiro, Instituto de Física, Rio de Janeiro, RJ, Brasil. \\ ${ }^{2}$ Universidade Federal de Juiz de Fora, Departamento de Física, Juiz de Fora, MG, Brasil.
}

\begin{abstract}
Recebido em 22 de janeiro de 2021. Revisado em 13 de fevereiro de 2021. Aceito em 17 de fevereiro de 2021.
Esta é uma resenha que tem como objetivo apresentar as principais ideias da Parte IV do livro Origens, em que os autores são Neil Degrasse Tyson e Donald Goldsmith. Neste livro é feita uma viagem de 14 bilhões de anos de evolução cósmica, mostrando diversos conceitos sobre questões que envolvem a origem do universo e de tudo contido nele. Todos os conceitos científicos são construídos a partir de modelos simples, levando o leitor a percorrer os passos de como se formou o Sistema Solar e como ele foi utilizado como parâmetro para hipóteses de formação planetária. Posteriormente é apresentado os métodos de busca e detecção de exoplanetas. Os autores possuem uma preocupação constante em conduzir o leitor de forma que esse entenda o funcionamento e a relevância de cada um dos assuntos científicos abordados. Pode-se dizer que o livro fornece de forma satisfatória um conteúdo científico complexo de maneira acessível até para leitores que não são da área. Vale salientar ainda que a parte IV, em particular, aqui é utilizado como ferramenta de ensino e desenvolvimento introdutório ao estudo da formação planetária, contemplando desde curiosos à iniciantes no estudo desta área, sem as cobranças e complexidades físicas de costume.
\end{abstract}

Palavras chaves: Formação Planetária, Exoplanetas, Divulgação Científica.

This is a review that aims to present the main ideas of Part IV of the book Origins, in which the authors are Neil Degrasse Tyson and Donald Goldsmith. In this book, a journey of 14 billion years of cosmic evolution is made, showing various concepts on issues that involve the origin of the universe and everything contained in it. All scientific concepts are built from simple models, leading the reader to go through the steps of how the Solar System was formed and how it was used as a parameter for hypotheses of planetary formation. Methods for searching and detecting exoplanets are presented. The authors are constantly concerned with guiding the reader so that he understands the functioning and relevance of each of the scientific subjects covered. It can be said that the book satisfactorily provides complex scientific content in an accessible manner even for readers who are not in the field. It is also worth noting that part IV, in particular, can easily be used as an introductory teaching and development tool for the study of planetary formation, covering from curious to beginners in the study of this area, without the usual physical demands and complexities.

Keywords: Planetary Formation, Exoplanets, Outreach.

O livro de Neil DeGrasse Tyson em parceria com Donald Goldsmith teve a sua primeira publicação em 2004, sendo republicado no ano de 2015, no Brasil, com tradução de Rosaura Eichenberg pela editora Planeta. Origens possui uma escrita poética e instigante, em que apesar de Tyson ser um grande divulgador científico e a figura principal do livro, não se pode desconsiderar a participação de Goldsmith, que nos apresenta a história do universo construindo detalhes, recheados de conceitos físicos, de uma maneira leve e ritmada.

O livro é dividido em cinco partes que se estendem desde a origem do Universo à origem da Vida. Dessa forma, a primeira parte é intitulada "A origem do Universo" e é discutida hipóteses de origem de tudo que existe. Na segunda parte é discutido a origem

\footnotetext{
*Endereço de correspondência: may.mmarques@gmail.com
}

das galáxias e a estrutura cósmica. Posteriormente, na terceira parte são apresentados conceitos e teorias sobre "A origem das estrelas". A Parte 4, que é o foco principal desta resenha é intitulada como "A origem dos planetas". Nesta quarta parte é feita uma divisão em três capítulos, "Quando os mundos eram jovens", "Entre os mundos", "Mundos inumeráveis: planetas além do sistema solar". Por fim, a quinta e última parte está relacionada a um debate sobre a origem da Vida, que inclusive é o título desta Parte 5.

Na parte 4 do livro Origens, Tyson e Goldsmith fazem uma viagem da grande "hipótese nebular" de Immanuel Kant, e vão até as teorias atuais construídas através de observações astronômicas e muita matemática, sobre a origem e formação dos planetas. Primeiramente, são apresentadas as ideias de Kant, onde o Sistema Solar e tudo que está contido nele teria sido formado por 
uma nebulosa feita majoritariamente de gás e poeira. De acordo com os autores, esta teoria ganhou mais forma e acabamento matemático com o tempo [1]. Vale salientar que a ideia principal desenvolvida por Kant da formação planetária segue firme até os dias atuais.

O livro nos deixa claro que quanto mais informações conseguimos obter mais questionamentos surgem. As certezas que tínhamos observando apenas o Sol e os nossos vizinhos no Sistema Solar foram colocadas à prova quando na década de 1990 foi descoberto o primeiro exoplaneta.

No primeiro capítulo da Parte IV vemos como a estrutura do Sistema Solar foi construída, com planetas rochosos mais próximos do Sol, e os gigantes gasosos posicionados mais externamente. É apresentado o conceito dos planetesimais e como de pequenos grãos de poeira surgiram os grandes corpos que orbitam o Sol. É importante mencionar que não somente os planetas surgiram desse processo, mas também as suas respectivas luas, os asteroides, cometas e todo o tipo de material rochoso pertencente ao Sistema Solar 2 .

No capítulo seguinte o foco são justamente os materiais que circundam e preenchem o vazio dos sistemas. Resumidamente, este vazio no universo, na verdade é cheio de campos magnéticos e gravitacionais, além de muita poeira cósmica [2] Sobre o caso do sistema solar é mostrado como no início da formação planetária havia choques constantes entre os corpos, evidenciados a partir das crateras marcadas nos planetas que não possuem atividade geológica. Os autores também falam sobre as regiões que abrigam trilhões de corpos no sistema solar, como o cinturão de asteroides entre Marte e Júpiter, a Nuvem de Oort e o Cinturão de Kuiper, onde encontramos Plutão e o cometa mais famoso de todos, Halley.

No terceiro e último capítulo desta parte o foco são os exoplanetas. Neste capítulo são apresentadas as contradições que encontramos ao descobrirmos gigantes gasosos em órbitas próximas as estrelas que orbitam, inclusive, órbitas muito mais curtas do que as encontradas no Sistema Solar. Os autores discorrem sobre o método de detecção por efeito Doppler, método principal de detecção na época do texto, como através dele conseguimos coletar informações importantes sobre a órbita e até mesmo uma estimativa da massa do planeta. Além disso, apontam os principais problemas da utilização desse método, que limita as buscas a planetas massivos e com órbitas curtas.

De forma geral, a leitura da Parte IV do livro Origens serve de material para o início dos estudos da formação planetária. O conteúdo tem desenvolvimento acessível e leve dos principais tópicos relacionados à temática. Apesar de alguns dados desatualizados, conforme apontado na edição utilizada para construção dessa resenha, os autores nos fornecem a base conceitual teórica da física necessária para aprofundamento de estudos sobre a formação planetária, estudo de exoplanetas e os métodos de detecção.

\section{Agradecimentos}

Gostaria de agradecer, primeiramente, ao meu orientador Bruno do Nascimento Dias por ser um excelente orientador e acreditar no meu trabalho. Gostaria de agradecer aos revisores anônimos da Revista pelos comentários e sugestões que proporcionaram a melhora deste texto.

\section{REFERÊNCIAS}

[1] N.D. Tyson, Origens (Editora Planeta do Brasil, São Paulo, 2015).

[2] J.A.F. Pacheco, Vida no Universo (Editora Edusp, São Paulo, 2020). 